\title{
Sistema de Integração Ensino-Serviço-Comunidade: relato de experiência das ações realizadas nas Faculdades de Saúde e Medicina da UnB
}

Dyana Helena de Souza, Carla Targino Bruno dos Santos, Dayde Lane Mendonca da Silva, Claudia Maffini Griboski, Dais Goncalves Rocha

\section{Resumo}

Desde 2016 as Faculdades de Ciências da Saúde e Medicina da Universidade de Brasília (UNB) integram o Projeto Educação pelo Trabalho (PET-GraduaSUS), desenvolvendo ações colaborativas entre os cursos de Enfermagem, Farmácia, Medicina, Nutrição, Odontologia e Saúde Coletiva numa perspectiva de adequação às Diretrizes Curriculares Nacionais - DCN, com a ampliação das ações conjuntas por meio dos cenários de prática, Educação Permanente e Integração Ensino-ServiçoComunidade. O objetivo deste projeto reside na consolidação do Sistema Saúde Escola e no fortalecimento da integração ensino-serviço-comunidade, promovendo a interprofissionalidade e o trabalho em equipe. A atuação conjunta entre os cursos fortalece a formação interprofissional de modo a possibilitar a melhoria da qualidade da educação na área da saúde. A educação pautada na interprofissionalidade vai além de uma contraposição ao modelo tradicional de ensino, onde cada profissão é pensada e discutida em si, trazendo uma proposta de participação dos diversos saberes na construção de um cuidado integral em saúde (CIHC, 2007; WHO, 2010). O Programa Nacional de Reorientação da Formação Profissional em Saúde (PróSaúde) e o Programa de Educação pelo Trabalho para a Saúde (Pet-Saúde) são a materialização dos preceitos constitucionais contidos no Artigo 200 da Carta Magna Brasileira de 1988 que prevê a formação de recursos humanos na área de saúde, e no artigo 27 da Lei Orgânica da Saúde (Lei 8.080/1990), onde além da organização de um sistema de formação de recursos humanos prevê que os serviços públicos que integram o Sistema Único de Saúde (SUS) constituem campo de prática para ensino e pesquisa. Nesta perspectiva, criou-se o Sistema de Integração Ensino-Serviço-Comunidade (SIESCO) da UNB, concebido no desejo de fortalecer a integração curricular, favorecendo a interface de saberes entre os cursos da Faculdade de Ciências da Saúde (FS) - Enfermagem, Farmácia, Nutrição, Odontologia e Saúde Coletiva - e de Medicina (FM) da UnB, por meio de atividades de caráter interprofissional numa relação ativa centrada no ensino-serviço-comunidade. O SIESCO é constituído pelas seguintes unidades de Gestão: Gestão de Apoio Pedagógico e Interprofissional (GAPI), Gestão dos Cenários de Prática - (GCP), Gestão de Pesquisa e Formação (GPF) e Gestão de Integração EnsinoServiço-Comunidade (GIESCO), e tem com o objetivo fomentar e integrar projetos na construção de competências e habilidades que valorizam o significado da experiência e a individualidade do estudante no contexto real das práticas de saúde nos diferentes níveis de atenção. Desta forma, busca-se a avaliação crítica das intervenções e a resolução de problemas de saúde, articulando as dimensões individuais e coletivas inseridas nas práticas de saúde e tendo como pano de fundo a integração entre as realidades do serviço e do ensino (WHO, 2010). O objetivo deste relato de experiência é compartilhar as ações desenvolvidas pela Unidade de Gestão dos Cenários de Prática do SIESCO em 2017, sob a ótica da educação interprofissional. Trata-se de um relato de experiência que contempla as atividades principais desenvolvidas pelo GCP-SIESCO, relacionadas ao Acolhimento, Estágio Interprofissional e Mostras de Estágios. A unidade GCP tem como objetivo apoiar os cursos na mobilização dos cenários de prática com ênfase na interdisciplinaridade e na relação interprofissional. É conduzido por uma comissão composta por docentes nomeados como coordenadores de estágio de cada curso envolvido. O Acolhimento utilizou-se de oficinas de avaliação e planejamento junto ao serviço e a comunidade. $O$ Estágio Interprofissional 66 
desenvolveu-se por meio de metodologias ativas, onde a orientação pedagógica valoriza os princípios da aprendizagem significativa e o estabelecimento de vínculo entre o conhecimento discente e a realidade de saúde a qual ele interage, e recebeu a participação de outros cursos como Serviço Social e Psicologia. As Mostras de Estágios ocorreram no formato de eventos de extensão com a participação ativa dos estudantes, docentes, serviço e comunidade. A região de saúde que recebeu as atividades desenvolvidas é a Regional de Saúde Leste do Distrito Federal, que envolve as regiões administrativas do Paranoá, Itapoã e São Sebastião. A realização do Acolhimento Interprofissional nos Cenários de Prática aconteceu no início do primeiro e segundo semestre de 2017, em São Sebastião, reunindo aproximadamente 95 participantes em cada. O acolhimento tem por objetivo favorecer a integração entre os cursos da FS (Enfermagem, Farmácia, Nutrição, Odontologia e Saúde Coletiva) e FM (Medicina), envolvendo os gestores dos serviços de saúde, estagiários, residentes, professores, estudantes e usuários dos serviços. O Acolhimento Interprofissional nos Cenários de Prática permitiu, por meio destes encontros, pactuar uma agenda comum entre os diferentes cursos e serviços de saúde, bem como planejar ações conjuntas durante o semestre visando a interprofissionalidade das ações (PARREIRA et al, 2016). O Acolhimento permitiu uma avaliação das ações desenvolvidas pela UNB nos cenários de prática, e possibilitou o alinhamento das ações desenvolvidas pelos cursos da FS/FM com as necessidades do serviço e da comunidade. As V e VI Mostra de Estágios, realizadas respectivamente nos dias 22 e 23 de junho, e nos dias 23 e 24 de novembro do presente ano, tiveram como principal objetivo dar visibilidade às diferentes atividades, materiais e produtos elaborados pelos alunos ao longo do semestre. A Mostra de Estágios é uma atividade semestral e possibilita desde sua organização até a apresentação dos trabalhos, uma articulação entre os diferentes cursos envolvidos (Enfermagem, Farmácia, Medicina, Nutrição, Odontologia e Saúde Coletiva) e também mostrar as ações realizadas nos diferentes cenários de práticas, permitindo conexões interdisciplinares. Foi perceptível o crescimento das Mostras de Estágios, na sua última edição com mais de 100 resumos relatando as experiências nos cenários de práticas e proporcionando a integração entre os cursos da área da saúde e afins da UNB. A sistematização das experiências é de grande importância para visualização de como tem acontecido a integração ensinoserviço-comunidade, e também para apontar os resultados e desafios de cada semestre. O Estágio Interprofissional, integrando universidade, serviço de saúde e uma escola de ensino fundamental do Paranoá, desenvolveu atividades de prevenção à violência e promoção da saúde. O estágio envolveu estudantes de graduação de farmácia, saúde coletiva, serviço social e psicologia, além de professores do ensino fundamental, preceptores dos serviços saúde, estudantes de pós-graduação, bolsistas de extensão e voluntários do PET-GraduaSUS. O Estágio seguiu a metodologia do Arco de Maguerez e as ações foram realizadas utilizando metodologias ativas para construção das oficinas na escola, construindo de maneira conjunta e participativa dos diferentes atores, proporcionando um compartilhamento de saberes. Como resultado positivo do estágio e em preocupação com a sustentabilidade das ações, ele será ampliado, como projeto de extensão permitindo a inserção de estudantes e docentes de outros cursos da UnB, ampliando também, os cenários de atuação. Consideramos a importância de uma formação numa perspectiva interprofissional (Milburn \& Colyer, 2008) em saúde que consiga articular com os diferentes grupos profissionais. As experiências apresentadas foram construídas por meio do trabalho em equipe de diversos atores que reconhecem a necessidade de um saber compartilhado e construído de forma coletiva. Reconhecemos que uma formação sem contato com outras áreas limita a comunicação e realização de ações pautadas na integralidade. O SIESCO é uma unidade de integração "viva" composta por grupos de aprendizagem tutoriais, em áreas estratégicas para o serviço público de saúde, que se caracterizam como instrumento para qualificação em serviço dos profissionais da saúde, de iniciação ao trabalho, geração de conhecimento e formação discente na área da saúde.

Descritores: Educação, SUS, Recursos Humanos em Saúde, Intersetorialidade 